\title{
Radioisotopic Labeling
}

National Cancer Institute

\section{Source}

National Cancer Institute. Radioisotopic Labeling. NCI Thesaurus. Code C73481.

A laboratory procedure that results in the incorporation of a radioactive isotope into a molecule of interest. 